\title{
Epidrug-induced upregulation of functional somatostatin type 2 receptors in human pancreatic neuroendocrine tumor cells
}

\author{
Marije J. Veenstra ${ }^{1}$, Peter M. van Koetsveld ${ }^{1}$, Fadime Dogan ${ }^{1}$, William E. Farrell ${ }^{2}$, \\ Richard A. Feelders ${ }^{1}$, Steven W.J. Lamberts ${ }^{1}$, Wouter W. de Herder ${ }^{1}$, Giovanni \\ Vitale $^{3,4}$, Leo J. Hofland ${ }^{1}$ \\ ${ }^{1}$ Department of Internal Medicine, Division of Endocrinology, Erasmus MC, Rotterdam, The Netherlands \\ ${ }^{2}$ Department Human Disease and Genomics Group, Institute of Science and Technology in Medicine, School of Medicine, \\ Keele University, Keele, United Kingdom \\ ${ }^{3}$ Laboratory of Endocrine and Metabolic Research, Istituto Auxologico Italiano IRCCS, Milan, Italy \\ ${ }^{4}$ Department of Clinical Sciences and Community Health (DISCCO), University of Milan, Milan, Italy \\ Correspondence to: Leo J. Hofland, email: I.hofland@erasmusmc.nl \\ Keywords: pancreatic neuroendocrine tumor; somatostatin receptor type 2; epigenetics; BON-1; QGP-1 \\ Received: November 19, 2015 Accepted: April 24, 2016 Epub: May 19, 2016 Published: March 13, 2018 \\ Copyright: Veenstra et al. This is an open-access article distributed under the terms of the Creative Commons Attribution License 3.0 \\ (CC BY 3.0), which permits unrestricted use, distribution, and reproduction in any medium, provided the original author and source \\ are credited.
}

\section{ABSTRACT}

Somatostatin receptors are a pivotal target for treatment of pancreatic neuroendocrine tumors (PNET), either with somatostatin analogues (SSA) or radiolabeled SSA. The highest affinity target for the most commonly used SSA is the somatostatin receptor type $2\left(s s t_{2}\right)$. An important factor that may complicate treatment efficacy, is the variable number of receptors expressed on pNETs. Gene expression is subject to complex regulation, in which epigenetics has a central role. In this study we explored the possible role of epigenetic modifications in the variations in $s t_{2}$ expression levels in two human pNET cell lines, BON-1 and QGP-1. We found upregulation of $s s t_{2}$ mRNA after treatment with the epidrugs 5-aza-2'-deoxycytidine (5-aza-dC) and valproic acid (VPA), an increased uptake of radiolabeled octreotide, as well as increased sensitivity to the SSA octreotide in functional cAMP inhibition. At epigenetic level we observed low methylation levels of the $s t_{2}$ gene promoter region irrespective of expression. Activating histone mark H3K9AC can be regulated with epidrug treatment, with an angle of effect corresponding to the effect on mRNA expression. Repressive histone mark $\mathrm{H} 3 \mathrm{~K} 27 \mathrm{me} 3$ is not regulated by either 5 -aza-dC or VPA. We conclude that epidrug treatment, in particular with combined 5-aza-dC and VPA treatment, might hold promise for improving and adding to current SSA treatment strategies of patients with pNETs.

\section{INTRODUCTION}

Pancreatic neuroendocrine tumors (pNET) can be divided into two categories, e.g. functioning and nonfunctioning. Functioning tumors, e.g. insulinoma and glucagonoma, overexpress pancreatic hormones, which may lead to devastating paraneoplastic syndromes. Nonfunctioning tumors, which are the majority of pNETs, have neuroendocrine histology, however no hormonal syndrome associated with hypersecretion.
A primary target for medical treatment of pNETs is the somatostatin receptor (SSTR) type 2(sst $\left.{ }_{2}\right)$ [1]. The primary goal of $s s t_{2}$ targeted treatment is the control of excessive hormone secretion by functional tumors. Furthermore, the role of SSAs in the control and/or reduction of tumor progression has been studied in recent years. Two randomized double blind placebo controlled studies (PROMID and CLARINET) showed a growth reducing effect of both long acting octreotide and -lanreotide on midgut and pancreatic NETs [2, 3]. 
An additional important class of analogues is the radiolabeled SSAs. Radiolabeled SSAs are of significant importance for tumor imaging, localization and diagnosis [4]. In addition, they are used for peptide receptor radionuclide therapy (PRRT), an important treatment option for pNETs, particularly in inoperable and/or metastasized tumors [5]. Sufficient uptake levels of radiolabeled SSAs are essential and a higher uptake leads to a higher remission rate. As such, the number of SSTR expressed on the tumor cell may be important for the efficiency of treatment. High uptake on the pretreatment octreoscan is thus crucial for treatment outcome, next to high patient performance [5]. Moreover, it has been described that neoadjuvant treatment with PRRT could increase the number of patients eligible for surgery, as adjuvant treatment may decrease the chance of tumor spread following surgery or reduces growth of already present micrometastases [6].

Sst as being the SSTR to which octreotide and lanreotide bind with the highest affinity, makes this receptor the most important target receptor for treatment efficacy [7]. Okuwaki et al. showed the relationship between $s s t_{2}$ protein expression and survival in pNET patients [8]. This study also shows that $s s t_{2}$ expression is not present or not equally high in every pNET, limiting treatment options for patients with very low or no expression. To the best of our knowledge, no DNA mutations have been found in the $s s t_{2}$ gene that could account for low protein levels in a number of the patients.

Cells have various mechanisms to regulate gene expression, one of which is epigenetic regulation. Epigenetics comprises various modes of gene expression management that can interfere with transcription factors targeting gene promoters. Modifications to the epigenome, that include $\mathrm{CpG}$ island methylation and a wide range of histone modifications, impact on and can modulate gene expression. Alterations in the epigenetic regulatory system of a cell may also play a major role in cancer development and progression. Despite a gene being free of mutations, several epigenetic alterations can turn off tumor suppressor genes or turn on oncogenes, e.g. by chromatin condensation or hypermethylation of $\mathrm{CpG}$ islands in the promoter regions.

Because of the pliable nature of epigenetic modifications, it is possible to induce changes chemically. In recent years several drugs have been exploited that can reverse $\mathrm{CpG}$ methylation and others that inhibit histone de-acetylation. Two of these so-called epidrugs are the DNA methyltransferase inhibitor (DNMTi) 5-aza2'-deoxycytidine (5-aza-dC) and histone deacetylase inhibitor (HDACi) valproic acid (VPA).

Torrisani et al. identified a novel transcription start site (tss) in $s s t_{2}$, upstream from the first described transcription start site by Petersenn et al. in 1999 [9, 10]. CpG methylation levels around the upstream tss are inversely associated with mRNA expression levels in several cell lines. In the investigated panel of cell lines it was found that epidrug treatment significantly increased $s s t_{2}$ expression in cell lines with low base line expression. Recently, Sun et al. described that VPA inhibited growth of BON-1 cells [11]. In their studies, VPA treatment induced cell cycle arrest as well as apoptosis. Furthermore, Greenblatt et al. previously showed that BON-1 cell xenografts in mice treated with VPA grow at a slower rate than in control mice [12].

In order to determine whether epigenetic mechanisms may be involved in the functional expression of $s t_{2}$ in pNET cells, we studied two well characterized pNET cell line models, BON-1 and QGP-1 [13-15]. We present data on the expression and functionality of $s s t_{2}$ in untreated cells, as wells as in cells after treatment with the epidrugs 5-aza-dC and VPA. We studied whether epigenetic changes and regulation could be responsible for variations in $s s t_{2}$ expression and functionality. The effect of 5-aza-dC and VPA on $s s_{2}$ expression, on uptake of radiolabeled $s s t_{2}$-preferring SSA, cAMP signaling, promoter $\mathrm{CpG}$ methylation, as well as enrichment of activating histone mark H3K9Ac and repressive histone mark $\mathrm{H} 3 \mathrm{~K} 27 \mathrm{me} 3$ is reported. The ultimate future goal is being able to increase sst ${ }_{2}$ expression and/or signaling in pNET patients, in order to improve response to- and optimize the effect of SSA treatment and PRRT.

\section{RESULTS}

\section{SSTR subtype mRNA expression}

In BON-1 cells $s s t_{1}(1.3 \pm 0.31$; mean \pm SEM $)$ is expressed at the highest level relative to $\operatorname{sst}_{5}(0.31 \pm$ $0.062)$ and $s s t_{2}(0.087 \pm 0.013)$. Sst $t_{3}$ levels were very low $(0.011 \pm 0.0030)$ (Figure $1 \mathrm{~A})$. Compared to BON-1 cells, expression levels are generally low in QGP-1, with highest expression of $s s t_{2}(0.066 \pm 0.0096)$, followed by $s s t_{1}$ $(0.059 \pm 0.0084)$ and $s s t_{5}(0.027 \pm 0.0019) . S_{s} t_{3}$ expression is not detectable in QGP-1 cells (Figure 1B). Because in pNET treatment $s s t_{2}$ is the most important target receptor for SSAs like octreotide and lanreotide, we focused in the remaining part of our studies on this receptor subtype. For both cell lines $\mathrm{EC}_{50}$ concentrations for inhibition of cell growth were determined for 5 -aza-dC and VPA. In BON1 and QGP-1 EC E0 $_{50}$ values for 5-aza-dC were $100 \mathrm{nM}$ and $50 \mathrm{nM}$, respectively. For VPA, the $\mathrm{EC}_{50}$ values were 2.5 $\mathrm{mM}$ in BON-1 and $1 \mathrm{mM}$ in QGP-1 (data not shown). Cells were cultured in the absence or presence of $\mathrm{EC}_{50}$ concentrations of either 5-aza-dC, VPA or the combination of both drugs for 7 days. The two cell lines responded differentially to treatment with these drugs with respect to st $_{2}$ mRNA expression. In BON-1, 5-aza-dC and VPA alone significantly increase $s s t_{2}$ expression by 255 and $145 \%$, respectively. Furthermore, the combined treatment with 5-aza-dC and VPA enhanced expression by $770 \%$ (Figure 1C). In QGP-1 cells, 5-aza-dC alone stimulated $s s t_{2}$ expression by $635 \%$, while VPA inhibited receptor expression by $60 \%$. In addition, VPA also attenuated the 
stimulatory effect of 5-aza-dC in combined treatment to $160 \%$ stimulation (Figure 1D). $S s t_{1}, s s t_{3}$ and $s s t_{5}$ mRNA expression results for epi-drug treatment in both cell lines can be found in the Supplementary Figure 1. For both cell lines, the changes in receptor expression of $s s t_{1}, s s t_{3}$ and $s s t_{5}$ with epidrug treatment, are minimal compared to the changes in sst $_{2}$.

\section{Somatostatin receptor uptake}

Figure 2 shows the effect of epidrug pretreatment on the uptake (internalization) of the $s s t_{2}$ preferring

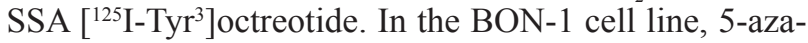
$\mathrm{dC}$ increased uptake of $\left[{ }^{125} \mathrm{I}_{-} \mathrm{Tyr}^{3}\right]$ octreotide by $185 \%$ and VPA by $595 \%$. The combined treatment with $\mathrm{EC}_{50}$ concentrations of 5-aza-dC and VPA significantly increased the uptake of $\left[{ }^{125} \mathrm{I}_{-} \mathrm{Tyr}^{3}\right]$ octreotide with $3820 \%$ (Figure 2A). In QGP-1 the effects of epidrug treatment are all stimulatory, although a statistically significant stimulation was observed only in cells that were treated with the combination of the drugs. Combined treatment with 5-aza-dC and VPA resulted in a statistically significant increased uptake of $\left[{ }^{125} \mathrm{I}_{-} \mathrm{Tyr}^{3}\right]$ octreotide by $300 \%$ (Figure 2B).

\section{Effect on cAMP production}

In order to evaluate whether epidrug treatment also could induce changes in the ability of the pNET cell lines to respond functionally to SSA treatment, we measured the effect of octreotide on forskolin-stimulated cAMP production in control and epidrug pretreated cells. Treatment of BON-1 cells with 5-aza-dC lowered the $\mathrm{EC}_{50}$ for the inhibitory effect of octreotide treatment on cAMP levels from $60 \mathrm{nM}$ in untreated control cells to $18 \mathrm{nM}$ in 5-aza-dC treated cells, indicating an enhanced effect of octreotide treatment at the level of cAMP inhibition (Figure 3A, 3B), although this difference did not reach statistical significance. VPA treatment did not explicitly influence the $\mathrm{EC}_{50}$ concentration (65 nM; Figure $3 \mathrm{C}$ ), while the combined treatment further reduced the
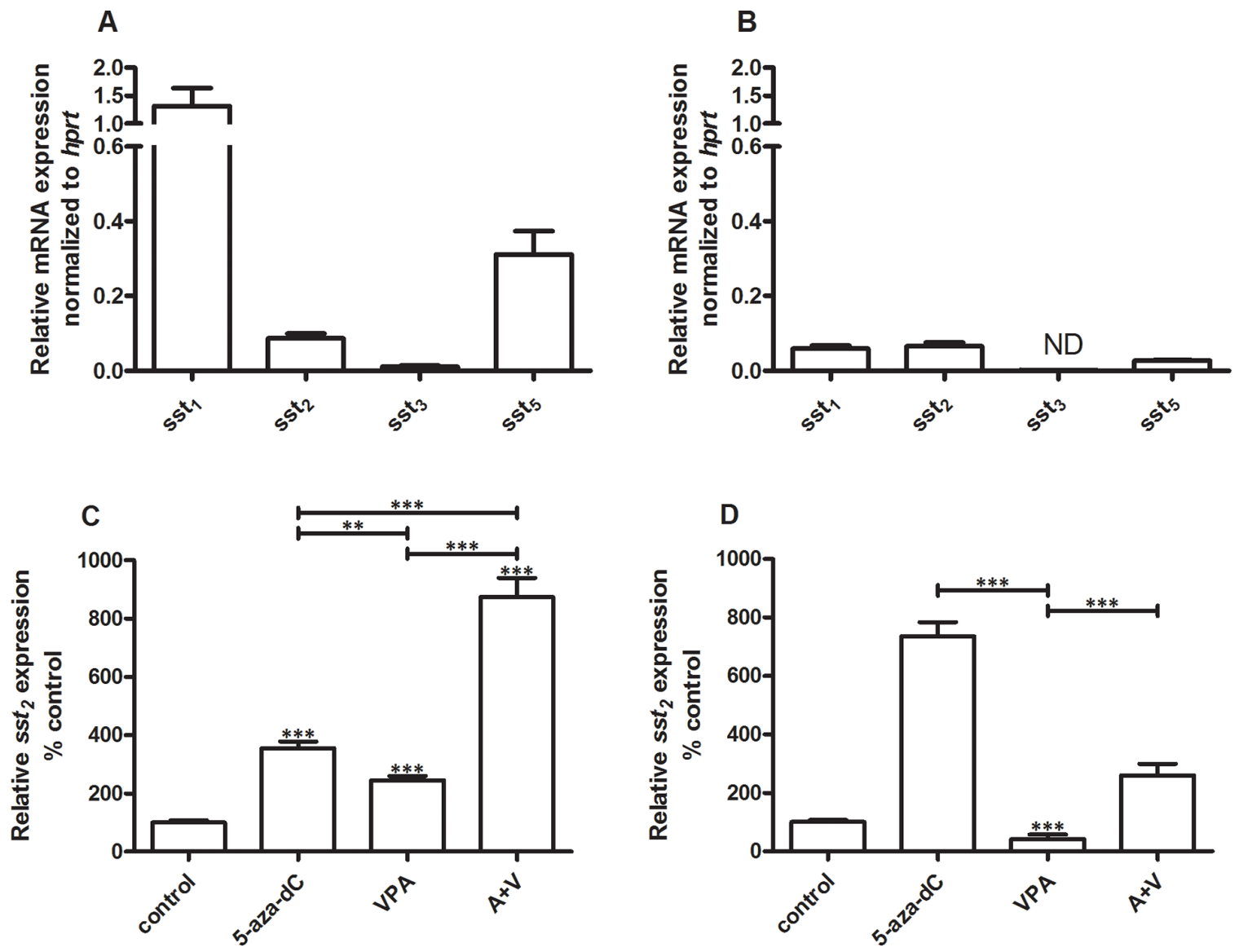

Figure 1: Ssts mRNA expression levels. Mean expression levels \pm SEM of $s s t s$ in BON-1 cells ( $\mathrm{n}=2$ ) A and QGP-1 cells ( $\mathrm{n}=3$ ) B, C. effect of treatment with 5-aza-dC $(100 \mathrm{nM})$, VPA $(2.5 \mathrm{mM})$ or the combination of both drugs on sst ${ }_{2}$ expression in BON-1 cells, D. effect of treatment with 5-aza-dC $(50 \mathrm{nM})$, VPA $(1 \mathrm{mM})$ or the combination of both drugs on sst ${ }_{2}$ expression in QGP-1 cells. Data are the mean \pm SEM and expressed as the percentage of untreated control cells. The expression levels were normalized to housekeeping gene $h p r t$. $* * \mathrm{p}<0.01, * * * \mathrm{p}<0.001$, ND: not detectable. 
inhibitory $\mathrm{EC}_{50}$ concentration of octreotide significantly to $1 \mathrm{nM}$ ( $\mathrm{p}<0.001$ compared to control) (Figure 3D).

In QGP-1 cells, we found a reverse effect of octreotide on forskolin-stimulated cAMP production. The response to octreotide in the untreated QGP-1 cells did not show a dose dependent reduction in cAMP levels, but instead a stimulatory effect, with an $\mathrm{EC}_{50}$ of $130 \mathrm{nM}$ in untreated cells (Figure $3 \mathrm{E}$ ). The $\mathrm{EC}_{50}$ was reduced to only $0.36 \mathrm{nM}$ in 5 -aza-dC treated cells (Figure $3 \mathrm{~F}$ ), while VPA reduced $\mathrm{EC}_{50}$ to $37 \mathrm{nM}$ and additionally lowered the maximal stimulation (Figure 3G). Combined treatment slightly increased the $\mathrm{EC}_{50}$ to $250 \mathrm{nM}$, and also lowered the maximal stimulation (Figure $3 \mathrm{H}$ ). None reached statistical significance.

\section{DNA methylation}

To determine the role of DNA methylation in $s s t_{2}$ regulation, methylation was quantitatively evaluated by pyrosequencing. The $\mathrm{CpG}$ sites studied were based on the work of Torrisani et al [9], who determined a number of CpG positions essential in the regulation of $s s t$, mRNA expression. These $\mathrm{CpG}$ positions are located in the promoter region, around the transcription start site. In both BON-1 cells and QGP-1 cells methylation levels were found to be low, all positions had under $10 \%$ methylation (Figure 4A and 4B). To verify the data, controls with high and low methylated DNA were sequenced in parallel as a positive and negative control. Figure 4C shows measured methylation levels between 85 and $96 \%$ and 2 and $7 \%$, respectively, validating the pyrosequencing data in BON-1 and QGP-1 cells.

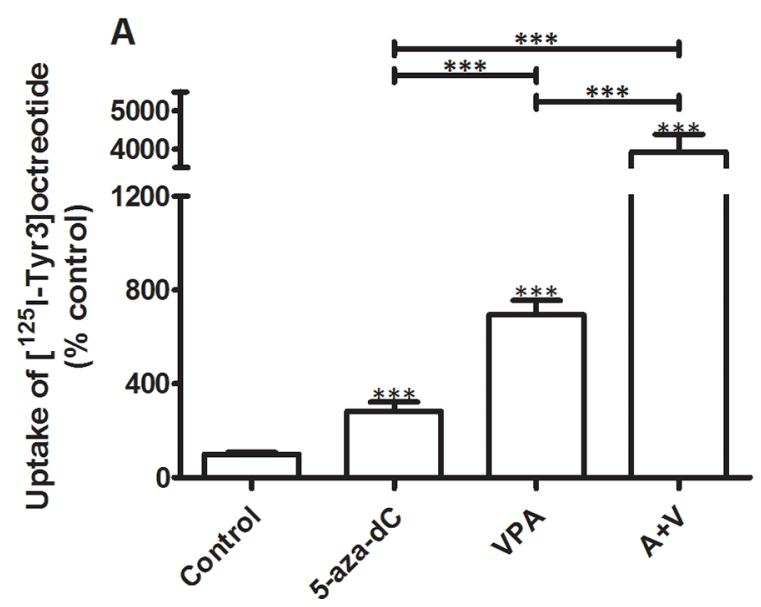

\section{Histone modification}

To assess the role of the histone code in the regulation of $s s t_{2}$ expression, we evaluated the presence of two marks in untreated cells and the change of these marks under the influence of epi-drug treatment. By means of chromatin immunoprecipitation (ChIP) we determined enrichment of the promoter region of $s s t_{2}$ for active transcription mark $\mathrm{H} 3 \mathrm{~K} 9 \mathrm{Ac}$ and for the repressive transcription mark H3K27me3.

Enrichment was determined at three positions in the $s s t_{2}$ promoter; at the transcription start site as described by Torrisani et al. and at two positions prior to this transcription start site [9]. Both modifications were detected in cell lines BON-1 and QGP-1. In BON1 cells, individual 5-aza-dC and VPA treatment lead to a slight increase of activating histone mark H3K9Ac on all three positions, although this does not reach statistical significance, except for VPA treatment at position -2 (Figure 5A). The drugs combined gave no significant change (Figure 5A). No statistically significant effect of 5-aza-dC was observed on repressive histone mark H3K27me3 at either of the positions, while VPA showed a trend to increased enrichment at positions -2 and -1 , which did not reach statistical significance, however (Figure 5B). H3K9Ac enrichment in QGP-1 cells is not influenced by VPA or combined treatment, while 5-aza-dC induces a statistically significant increase of the modification at position -1 relative to the tss (Figure 5C). Repressing histone mark H3K27me3 is in QGP-1 cells not influenced by either of the treatments relative to control (Figure 5D). In all experiments, efficiency was tested and confirmed with negative and positive control primers (data not shown).

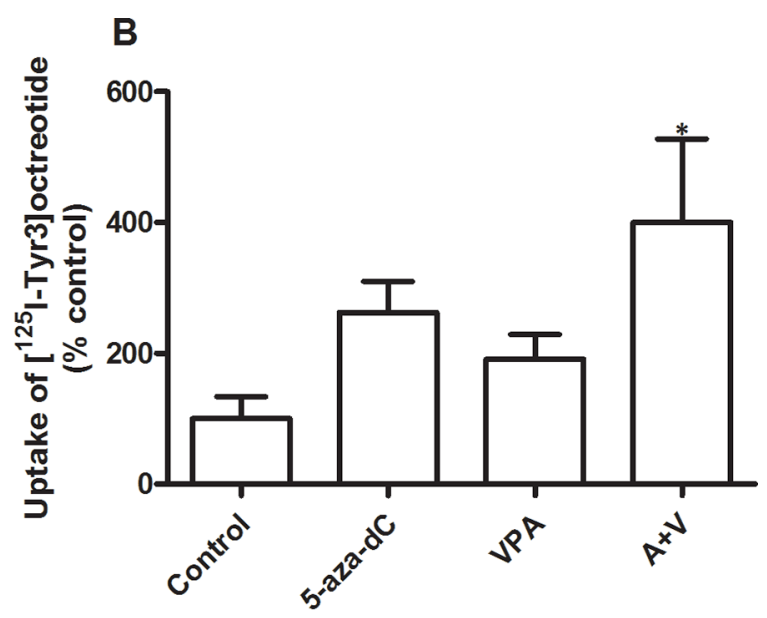

Figure 2: Uptake of radiolabeled $\left[{ }^{125} \mathrm{I}_{-} \mathbf{T y r}^{3}\right]$ octreotide. Specific uptake of radiolabeled $\left[{ }^{125} \mathrm{I}-\mathrm{Tyr}^{3}\right]$ octreotide by $\mathrm{BON}-1$ ( $\mathrm{n}=3$ ) and QGP-1 cells ( $\mathrm{n}=3)$, without and with treatment with 5-aza-dC (BON-1: $100 \mathrm{nM}$, QGP-1: $50 \mathrm{nM})$, VPA (BON-1: $2.5 \mathrm{mM}$, QGP-1: $1 \mathrm{mM})$, or their combination. Specific uptake was calculated as the difference between total uptake and the uptake in the presence of excess unlabeled octreotide. Values were corrected for differences in cell number as measured by the DNA content per well. Values are expressed as the percentage of untreated control. A. BON-1, B. QGP-1. * $p<0.05 * * * p<0.001$. Specific uptake values for control BON-1 cells amounted 0.14 $\pm 0.017 \%$ (mean $\pm \mathrm{SEM})$ and for QGP-1 $0.11 \pm 0.051 \%$ of added dose. 


\section{DISCUSSION}

$S s t_{2}$ is the highest affinity receptor for the conventional SSAs used in clinical setting, e.g. octreotide and lanreotide [7]. Expression of $s s t_{2}$ is highly variable between pNET patients [8, 16-19], where higher expression of $s_{s t} t_{2}$ is associated with better treatment results and better survival $[5,8]$. The ability to upregulate $s s t_{2}$ expression in pNETs could improve treatment efficacy.
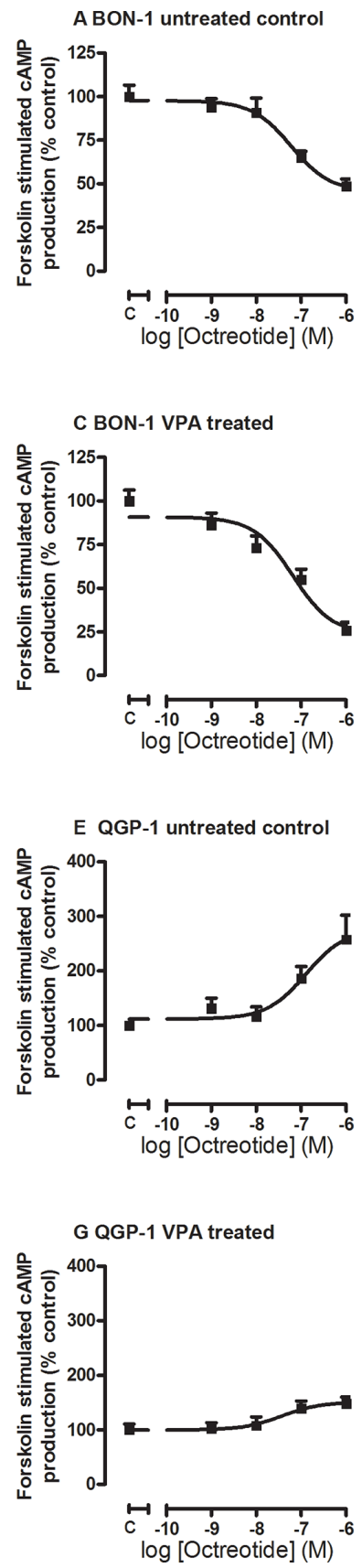

Epigenetic mechanisms play a key role in the regulation of gene expression [20]. DNMTs, HDACs and histone acetylases are some of the components involved in chromatin remodeling and, therefore, gene expression $[21,22]$. We chose to work with two epidrugs, capable of altering epigenetic marks and which are already being used clinically; the DNMTi 5-aza-dC and the HDACi VPA. We determined the $\mathrm{EC}_{50}$ for both drugs in both cell lines, based on their inhibitory effect on cell growth. The determined concentrations are clinically feasible.
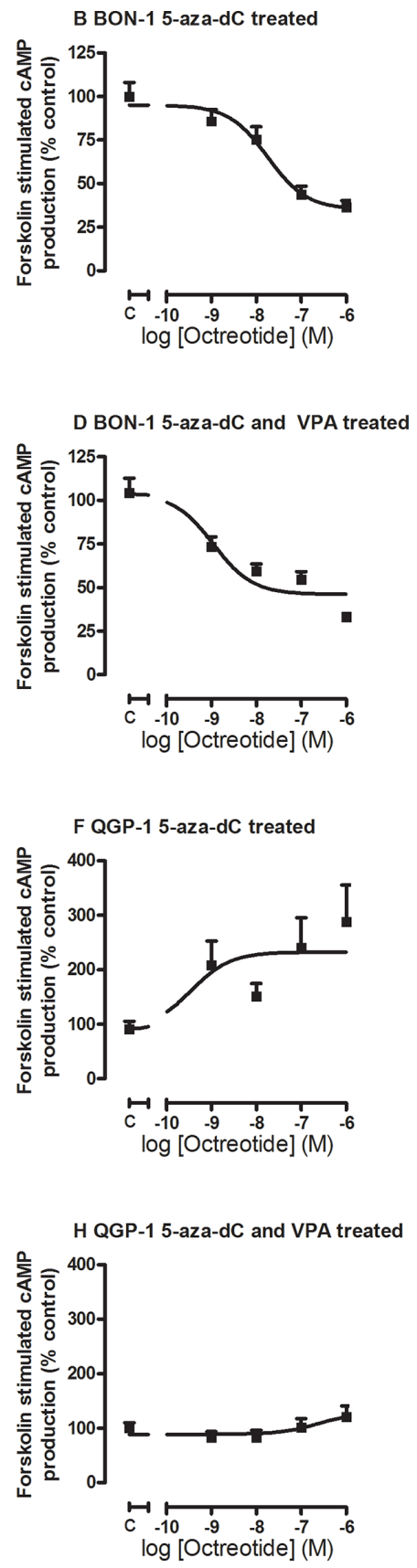

Figure 3: Octreotide-induced inhibition of forskolin-stimulated cAMP production. Octreotide-induced inhibition of forskolin-stimulated cAMP production in BON-1 A-D. $(n=3)$ and QGP-1 E-H. cells $(n=3)$, without or with treatment with 5-aza-dC (BON1: $100 \mathrm{nM}$, QGP-1: $50 \mathrm{nM}$ ), VPA (BON-1 $2.5 \mathrm{mM}$, QGP-1: $1 \mathrm{mM}$ ), or their combination. 

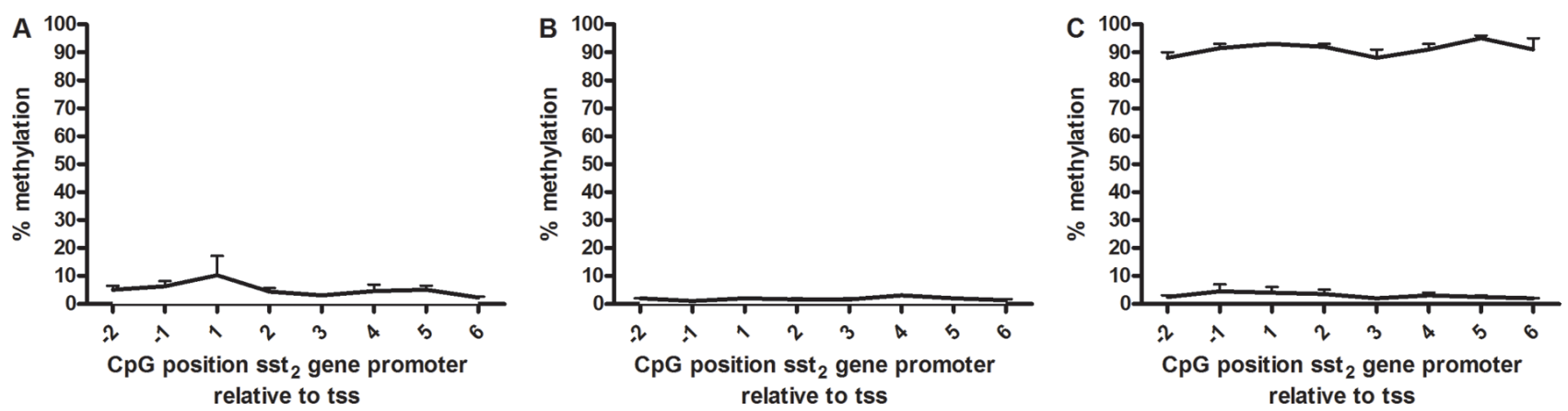

Figure 4: $\boldsymbol{S s t}$, promoter methylation. Percentage $s_{2}{ }_{2}$ promoter methylation of $\mathrm{CpG}$ positions surrounding the proximal transcription start site in A. BON-1 cells ( $\mathrm{n}=3$ ), B. QGP-1 cells $(\mathrm{n}=3)$ and $\mathbf{C}$. high and low methylated control DNA (all mean $\pm \mathrm{SEM}$ ). The transcription start site is located between -1 and 1 .
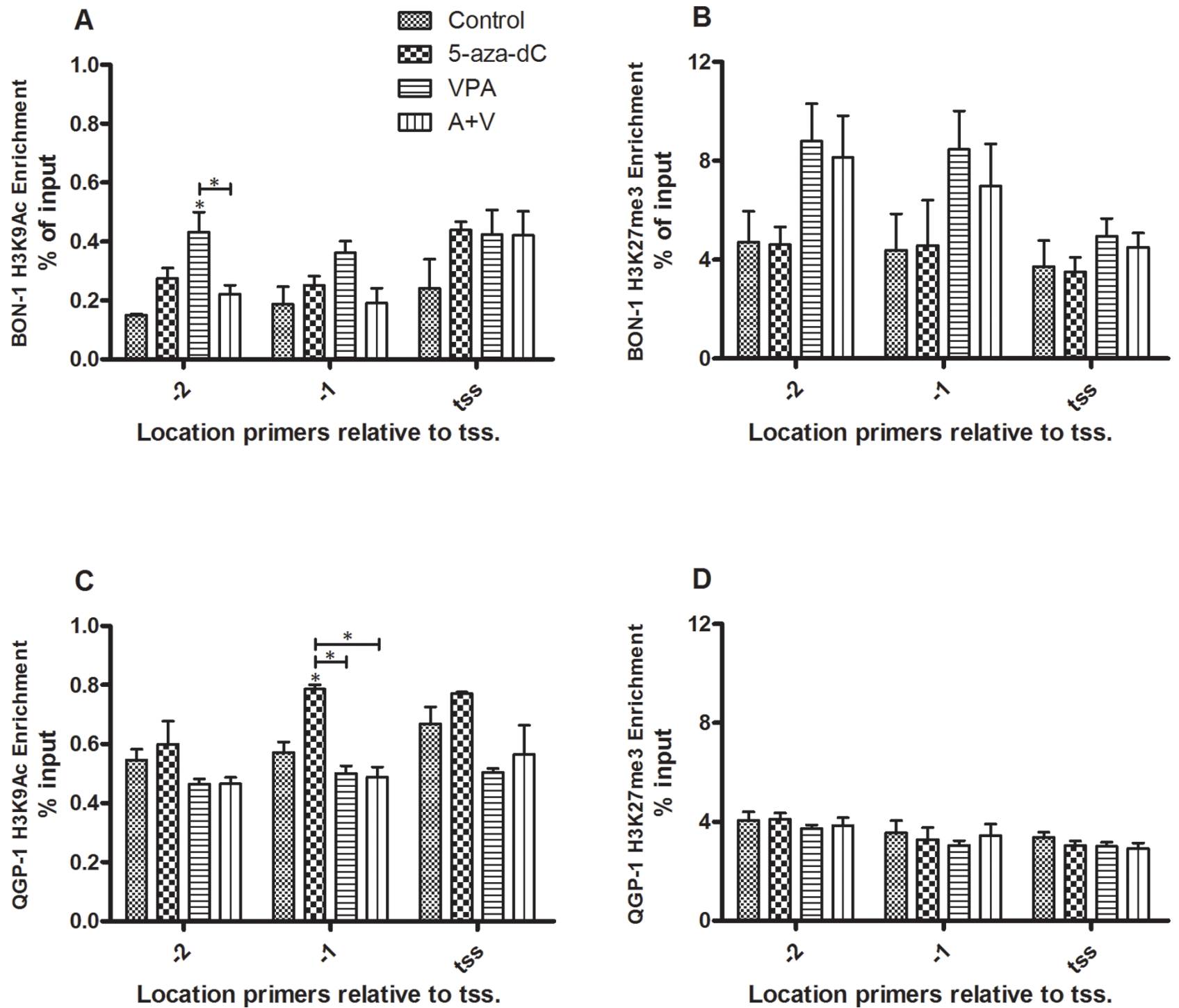

Figure 5: ChIP of histone marks H3K9Ac and H3K27me3 for the $s s t_{2}$ promoter. Enrichment of the sst $_{2}$ promoter as determined by ChIP for histone marks H3K9Ac and H3K27me3 (mean \pm SEM) in BON-1 and QGP-1 cells, without or with treatment with 5-aza-dC (BON-1: $100 \mathrm{nM}$, QGP-1 $50 \mathrm{nM}$ ), VPA (BON-1: $2.5 \mathrm{mM}$, QGP-1: $1 \mathrm{mM}$ ), or their combination. A. H3K9Ac in BON-1 cells (n=2) B. H3K27me3 in BON-1 cells ( $n=3)$ C. H3K9Ac in QGP-1 cells $(n=2)$ D. H3K27me3 in QGP-1 cells $(n=3)$ * $p<0.05$ vs untreated control. 
Plasma concentrations that are reached for 5-aza-dC in hematological malignancies and solid tumors range from $0.04 \mu \mathrm{M}$ to $5.6 \mu \mathrm{M}$ and were reached using different treatment schedules $[23,24]$. The $\mathrm{EC}_{50}$ concentrations of $100 \mathrm{nM}$ in BON-1 cells and $50 \mathrm{nM}$ in QGP-1 cells are within this range. The $\mathrm{EC}_{50}$ concentrations for VPA determined in both cell lines, $2.5 \mathrm{mM}$ in BON-1 cells and $1 \mathrm{mM}$ in QGP-1 cells, are close to therapeutically achievable serum concentrations, which range from 0.3 $\mathrm{mM}$ to $1 \mathrm{mM}[25,26]$.

The effect of 5-aza-dC and VPA on $s s t_{2}$ mRNA expression levels differed between the cell lines. In both cell lines 5-aza-dC stimulates expression, but in QGP-1 two times more efficiently. In contrast, VPA increases $s s t_{2}$ expression in BON-1, but is inhibitory in QGP-1. Moreover, while the effect of combined treatment leads to a considerably enhanced expression of $s s t_{2}$ in BON1 cells, VPA negatively interferes with the stimulating effect of 5-aza-dC in QGP-1, as expected from the effect of VPA alone in this pNET cell line. The increase in $s s t_{2}$ expression induced by VPA treatment of BON-1 cells is in agreement with previous observations by Sun et al. [11].

In order to demonstrate the effect of epidrug treatment on the uptake of the radiolabeled $s s t$, preferring SSA octreotide, sst, internalization studies were performed. In BON-1, 5-aza-dC and VPA treatment increased the uptake of $\left[{ }^{125} \mathrm{I}_{-} \mathrm{Tyr}^{3}\right]$ octreotide significantly. Combined treatment significantly increases uptake by nearly 40-fold, consolidating the enhanced effect of both drugs seen on $s s t_{2}$ mRNA expression. Unlike the effect on mRNA expression, VPA stimulates uptake more than 5-aza-dC in BON-1.

While there was an inhibitory effect of VPA in QGP-1 on $s s t,{ }_{2}$ mRNA expression, uptake of $\left[{ }^{125} \mathrm{I}_{-} \mathrm{Tyr}^{3}\right]$ octreotide was increased in VPA treated cells, as well as following 5-aza$\mathrm{dC}$ treatment. Combined treatment induced a statistically significant increased uptake, which was higher than each compound individually, albeit not fully additive. Increased uptake does not necessarily need to be the result of increased numbers of $s s t_{2}$ on the cellular membrane. An increase in turnover and redirection of the receptor to the membrane might also cause a higher amount of internalized $\left[{ }^{125} \mathrm{I}-\mathrm{Tyr}^{3}\right]$ octreotide [27]. The results of the internalization studies show that, if these data can be extrapolated to the in vivo situation, both compounds, and particularly the combination, could have a potential role in improving treatment efficiency of PRRT in patients with pNETs.

To further confirm the functional outcome of the epidrugs, we determined the effect of treatment on the efficacy of octreotide to inhibit cAMP production. Inhibition of cAMP is one of the main mechanisms via which $s s t_{2}$ activation results in inhibition of hormone release.

Octreotide inhibited forskolin-stimulated cAMP production in $\mathrm{BON}-1$ cells with an $\mathrm{EC}_{50}$ of $60 \mathrm{nM}$, which was markedly decreased by 5 -aza-dC treatment, to $18 \mathrm{nM}$. While VPA treatment had no distinct effect, leaving the
$\mathrm{EC}_{50}$ at $65 \mathrm{nM}$, combined treatment enhances octreotide sensitivity even more than 5-aza-dC alone, to an effective $\mathrm{EC}_{50}$ dose of $1 \mathrm{nM}$. These data suggest a shift in the potency of octreotide to inhibit cAMP production to a more $s s t_{2}$-like $\left(\mathrm{IC}_{50} 0.38-0.60 \mathrm{nM}\right)$ binding profile [7]. These data show that 5 -aza-dC could play a major role in increasing sensitivity to treatment with $s t_{2}$-preferring SSA, most likely by inducing an upregulation of $s s t_{2}$, and even more when combined with VPA. In untreated QGP-1 cells, octreotide treatment does not lead to inhibition of cAMP production, but instead increases cAMP expression with an $\mathrm{EC}_{50}$ of $130 \mathrm{nM}$. Pretreatment with 5-aza-dC considerably reduces the $\mathrm{EC}_{50}$ dose to $0.36 \mathrm{nM}$, and although the angle of the effect remains an increase of cAMP production, 5-aza-dC did reduce the $\mathrm{EC}_{50}$ of octreotide to a clinically relevant concentration. Also VPA treatment and combined treatment increased cAMP production, but in line with the reduced $s s t_{2}$-expression, VPA alone, as well as combined VPA/5-aza-dC treatment lowered the maximal response to octreotide. To the best of our knowledge increased cAMP production upon SSTR activation has been previously described only in porcine somatotroph cells [28]. Currently, it is unclear whether this process can be found in tumors of patients, and whether this could play a role in sensitivity to treatment. This remains to be investigated.

Considering the variable $s s t_{2}$ expression levels in pNETs [8, 16-19], and the absence of known mutations, epigenetic modifications of $s s t_{2}$ regulatory elements might explain these differences between patients. By pyrosequencing we analyzed $8 \mathrm{CpGs}$ present in the promoter region of the $s s t_{2}$ gene, which previously have been shown to be regulating $s t_{2}$ expression [9]. In both BON-1 and QGP-1 low methylation levels were detected, around only $3 \%$ in BON-1 and $2 \%$ in QGP-1. These low levels suggest that $\mathrm{CpG}$ hypermethylation in this region does not play a role in low $s s t_{2}$ expression or loss of expression, although a role of $\mathrm{CpG}$ methylation in other regions of the $s s t_{2}$ gene cannot be excluded.

Epigenetics, however, comprise a wide range of modifications, such as a large series of histone modifications, controlling chromatin accessibility. Two well-known histone marks, H3K27me3, associated with transcriptional repression, and $\mathrm{H} 3 \mathrm{~K} 9 \mathrm{Ac}$, associated with active gene transcription were studied. In BON1 , both 5 -aza-dC and VPA induced a slight increase in enrichment of active transcription mark H3K9Ac at all three studied positions, although this effect was only significant for VPA treatment at position -2. The general direction of the effect of treatment with 5-aza-dC and VPA on $s s t,{ }_{2}$ mRNA expression is reflected in the effect on enrichment of histone marks H3K9Ac in BON-1 cells. The effect on $\mathrm{H} 3 \mathrm{~K} 27 \mathrm{me} 3$ is contradictory, as the expected effect is downregulation, whereas an (nonsignificant) upregulation is seen after treatment with VPA and the combination. Similar observations were made in QGP-1 cells. The absence of an effect of 5-aza-dC on 
$\mathrm{H} 3 \mathrm{~K} 27 \mathrm{me} 3$, in combination with an increase in H3K9Ac in QGP-1, although not significant, is more in line with the observed increased $s t_{2}$ expression. In conclusion, H3K27me3 appears thus to be a histone mark that does not play a major role in regulation of the $s s t_{2}$ promoter, while $\mathrm{H} 3 \mathrm{~K} 9 \mathrm{Ac}$ does seem to play a role in activation of $s s t_{2}$ and is a good candidate for further studies.

As the treatment with epidrugs in our models is not selective in targeting genes, it cannot be excluded that indirect regulation of $s s t_{2}$ expression takes place. Transcription factors and other regulating factors might be upregulated or redirected, leading to increased mRNA expression. In addition, second messenger pathway participants might be influenced, or recycling of the receptor could be slowed, leading to enhanced functional response.

Currently, epidrugs have limited use in cancer treatment. Based on the results of this study, and the clinical trials performed so far with either 5-aza-dC or VPA or their combination [29, 30], these epidrugs alone or in combination, and with concomitant treatment with SSA, may be a future treatment approach in pNET patients that are otherwise not responding to- or suitable for any treatment.

In conclusion, the results of our study show that epidrug treatment, in particular with 5-aza-dC and VPA, might hold promise for improving current treatment strategies for patients with pNET with different types of $\mathrm{SSA}$, in particular in patients with difficult to treat pNETs with low $s s t_{2}$ numbers. However, further experiments are needed to validate whether a similar upregulation of $s s t_{2}$ expression and $s s t_{2}$ functionality can be achieved in vivo.

\section{MATERIALS AND METHODS}

\section{Cell culture}

In this study two human pNET cell lines were used, BON-1 [13] and QGP-1 [14]. BON-1 cells were a kind gift from Dr. Townsend (University of Texas Medical branch, Galveston, USA). QGP-1 cells were purchased from the Japanese Collection of Research Bioresources Cell Bank (JRCB, Osaka, Japan). Both cell lines were confirmed as mycoplasm-free. Using short tandem repeat profiling the identity of the BON-1 and QGP-1 cell lines was confirmed [15]. BON-1 cells were cultured in DMEM-F12 supplemented with FCS $(10 \% \mathrm{v} / \mathrm{v}) \mathrm{L}$-glutamine $(2 \mathrm{mmol} / \mathrm{L})$, fungizone $(0.5 \mathrm{mg} / \mathrm{L})$ and penicillin $\left(1 \times 10^{5} \mathrm{u} / \mathrm{L}\right)$. QGP-1 cells were cultured in RPMI-1640 supplemented with FCS (10\% v/v) and penicillin $\left(1 \times 10^{5} \mathrm{u} / \mathrm{L}\right)$. Cells were cultured in $75 \mathrm{~cm}^{2}$ culture flasks (Corning Life Sciences B.V., Amsterdam, the Netherlands) at $37^{\circ} \mathrm{C}$ in a $5 \% \mathrm{CO}_{2}$ humidified incubator and passaged by trypsinization every 7 days, with medium supplementation on the fourth day, until a maximum of 20 passages. For experiments cells were harvested with trypsin $(0.05 \%)$-EDTA $(0.53 \mathrm{mM})$ and plated in 12 or
24 well plates (Greiner Bio-one B.V., Alphen aan den Rijn, the Netherlands). All media and supplements were obtained from Gibco (Life Technologies, Bleiswijk, the Netherlands) except for penicillin (Astellas Pharma B.V. Leiden, the Netherlands).

\section{Compounds}

VPA sodium salt and 5-aza-dC powder were purchased from Sigma-Aldrich (Zwijndrecht, the Netherlands). VPA sodium salt was stored at $-20^{\circ} \mathrm{C}$ and freshly prepared by dissolving in culture medium prior to each experiment and compound refreshing. 5-aza-dC was dissolved in $\mathrm{H}_{2} \mathrm{O}$ at a concentration of $10^{-3} \mathrm{M}$, aliquoted and stored at $-20^{\circ} \mathrm{C}$.

\section{Cell proliferation assay}

To determine the optimal cell number for the culture of the cell lines in 24 well plates and determination of the $\mathrm{EC}_{50}$ concentrations for 5-aza-dC and VPA treatment, DNA measurement (as a measure of cell number) was performed. Cells were cultured and, in case of $\mathrm{EC}_{50}$ determination, treated in 24 well plates. Medium and compounds were refreshed after three days. After 7 days of treatment the medium was removed and cells were lysed with $150 \mu \mathrm{l}$ ammonia solution (1 mol/L)-Triton-X100 $(0.2 \% \mathrm{v} / \mathrm{v})$ per well and incubated 10 minutes at $4^{\circ} \mathrm{C}$. Plates were sonicated 5 seconds per well at an amplitude of 1400 microns to shear the DNA, and incubated for another 10 minutes at $4^{\circ} \mathrm{C}$. Per well $1 \mathrm{ml}$ assaybuffer $(100$ $\mathrm{mmol} / \mathrm{L} \mathrm{NaCl}, 10 \mathrm{mmol} / \mathrm{L}$ EDTA, $10 \mathrm{mmol} / \mathrm{L}$ Tris; $\mathrm{pH}$ 7.0) was added. Per well $20 \mu \mathrm{l}$ was pipetted into a cell star plate, 96 wells (Greiner), along with a standard curve of calf thymus DNA (Sigma) and $200 \mu$ l Hoechst 33258 (Sigma-Aldrich). Measurement was performed at 350 and $455 \mathrm{~nm}$ excitation and emission wavelengths respectively on a Victor X4 plate reader (Perkin Elmer, Waltham, Massachusetts, USA) and counts were referenced against the standard curve.

\section{Quantitative RT-PCR}

Quantitative RT-PCR was performed according to a method previously described $[31,32]$. In brief, poly A + mRNA was isolated from cells using Dynabeads oligo(dT) ${ }_{25}$ (Invitrogen Dynal AS, Oslo, Norway). The mRNA was eluted from the beads with 2 times $23 \mu \mathrm{l}$ $\mathrm{H} 2 \mathrm{O}$ incubated 2 minutes at $65^{\circ} \mathrm{C}$. Subsequently cDNA was synthesized with twice $20 \mu \mathrm{l}$, once with Reverse Transcriptase and once without. The cDNA is diluted five times, Q-PCR was done on $5 \mu$ sample with Taqman ${ }^{\circledR}$ Universal PCR mastermix (Applied Biosystems, Life Technologies) and detection using an ABI Prism 7900ht sequence detection system (Applied Biosystems). Primer and probe sequences are shown in Table 1. 
Table 1: Primer-probe sequences for Q-RT-PCR, PCR and sequencing primer sequences for pyrosequencing (Btn: biotin) and qPCR primer sequences for ChIP.

\begin{tabular}{|c|c|}
\hline cDNA primers & Sequence \\
\hline \multicolumn{2}{|l|}{ hprt } \\
\hline Forward & CAC TGG CAA AAC AAT GCA GAC T \\
\hline Reverse & GTC TGG CTT ATA TCC AAC ACT TCG T \\
\hline Probe & CAA GCT TGC GAC CTT GAC CAT CTT TGG A \\
\hline \multicolumn{2}{|l|}{ sst $_{1}$} \\
\hline Forward & CAC CGT GGC CAA GGT AGT AAA \\
\hline Reverse & CCA CGA TGG GCA GGA TGA \\
\hline Probe & CTG GGC GTG TGG GTG CTA TCG C \\
\hline \multicolumn{2}{|l|}{$s s t_{2}$} \\
\hline Forward & TCG GCC AAG TGG AGG AGA C \\
\hline Reverse & AGA GAC TCC CCA CAC AGC CA \\
\hline Probe & CCG GAC GGC CAA GAT GAT CAC C \\
\hline \multicolumn{2}{|l|}{ sst $_{3}$} \\
\hline Forward & CTG GGT AAC TCG CTG GTC ATC TA \\
\hline Reverse & AGC GCC AGG TTG AGG CTG TA \\
\hline Probe & CGG CCA GCC CTT CAG TCA CCA AC \\
\hline \multicolumn{2}{|l|}{$s s t_{5}$} \\
\hline Forward & CAT CCT CTC CTA CGC CAA CAG \\
\hline Reverse & GGA AGC TCT GGC GGA AGT T \\
\hline Probe & CCC GTC CTC TAC GGC TTC CTC TCT GA \\
\hline Pyrosequencing primers & sequence \\
\hline \multicolumn{2}{|l|}{ PCR } \\
\hline Forward & [Btn]GGG TTG GTT GGG TTA GTT TT \\
\hline Reverse & ATT CCT AAC TCC TCC ACC CTC TT \\
\hline \multicolumn{2}{|l|}{ Sequencing } \\
\hline Reverse strand & ACC TCA AAC TAA AAC TCT A \\
\hline ChIP primers & sequence \\
\hline \multicolumn{2}{|l|}{-2} \\
\hline Forward & TGC TGA CTG ACG TGG CTA CA \\
\hline Reverse & CGC ACC TGG AGT CCA AGA TT \\
\hline \multicolumn{2}{|l|}{-1} \\
\hline Forward & GTC CTT GCC ATG AGT CTT GA \\
\hline Reverse & CAG GCA GAG CTT ACA GAC AG \\
\hline \multicolumn{2}{|l|}{ tss } \\
\hline Forward & AGC GAA GCC GCT GTG ACG TA \\
\hline Reverse & TCT GGG CGC TGG TGG TCT TG \\
\hline
\end{tabular}




\section{Somatostatin receptor uptake}

SSTR internalization studies were performed as previously described with minor adjustments [33]. In short, cells of either cell line, BON-1 and QGP-1, were seeded in $75 \mathrm{~cm}^{2}$ culture flasks in $10 \mathrm{ml}$ regular culture medium on day 0 . On day 1 , four conditions were initiated; control, 5-aza-dC (BON-1: $\mathrm{EC}_{50} 100 \mathrm{nM}$, QGP1: $\mathrm{EC}_{50} 50 \mathrm{nM}$ ); VPA (BON-1: $\mathrm{EC}_{50} 2.5 \mathrm{mM}$, QGP-1: $\mathrm{EC}_{50} 1 \mathrm{mM}$ ); and combined 5-aza-dC and VPA treatment. Supplemental medium and compounds were added on day 3 . On day 6 , the cells are trypsinized and plated in 12 well plates $\left(1 \cdot 10^{6}\right.$ cells per well), 6 wells per treatment for triplicate incubation with either $\left[{ }^{125} \mathrm{I}_{-}-\mathrm{Tyr}^{3}\right]$ octreotide or $\left.{ }^{[25} \mathrm{I}_{-} \mathrm{Tyr}^{3}\right]$ octreotide and excess unlabeled octreotide to block internalization. On day 8, cells were washed twice with internalization medium (DMEM supplemented with HEPES (30 mM) (Sigma-Aldrich)), L-Glutamine (2 mM), sodium pyruvate $(1 \mathrm{mM})\left(\right.$ Gibco), penicillin $\left(10^{5} \mathrm{U} / \mathrm{L}\right)$, fungizone $(0.5 \mathrm{mg} / \mathrm{L})$ and $0.2 \%$ BSA (Sigma-Aldrich) (pH 7.4). Subsequently, $1 \mathrm{ml}$ of internalization medium per well was added to the cells, as well as 200,000 counts [ $\left.{ }^{125} \mathrm{I}-\mathrm{Tyr}^{3}\right]$ octreotide (final concentration $\sim 0.1 \mathrm{nM}$ ) was added to the wells and the plates were incubated at $37^{\circ} \mathrm{C}$ for 4 hours with or without excess unlabeled octreotide. After incubation the cells were washed twice with icechilled internalization medium. Low $\mathrm{pH}$ treatment with $1 \mathrm{ml}$ sodium acetate $(20 \mathrm{mM})$ (Sigma-Aldrich) in Hanks Balanced salt solution (Gibco), pH 5.0 (HBSS-Ac) was used to collect the membrane bound fraction of $\left[{ }^{125} \mathrm{I}_{-} \mathrm{Tyr}^{3}\right]$ octreotide. The cells were incubated for 10 minutes at $37^{\circ} \mathrm{C}$, subsequently the supernatant was collected (membrane fraction 1) and cells were washed one additional time with HBSS-Ac and supernatant collected (membrane fraction 2, membrane fraction data not shown). Finally, the cells were extracted with $1 \mathrm{M} \mathrm{NaOH}$, representing the internalized fraction of radioactivity. By Riastar (Perkin Elmer) internalized counts per million were determined in each treatment condition and fraction.

\section{Effect on cAMP production}

Cells were plated in $75 \mathrm{~cm}^{2}$ culture flasks and left to adhere for 2 days. Subsequently the cells were pretreated with no compound (vehicle); 5-aza-dC; (BON-1: $\mathrm{EC}_{50} 100$ $\mathrm{nM}$, QGP-1: $\mathrm{EC}_{50} 50 \mathrm{nM}$ ); VPA (BON-1: $\mathrm{EC}_{50} 2.5 \mathrm{mM}$, QGP-1: $\mathrm{EC}_{50} 1 \mathrm{mM}$ ); or 5-aza-dC and VPA combination for 5 days. After 5 days of incubation with drugs, the cells were trypsinized and plated in a 24 well plate $(0.1$ - $10^{6}$ cells per well) without or with compounds for an additional 2 days. After 2 days (total drug treatment period 7 days), the cells were incubated in triplicate without or with forskolin $\left(10^{-6} \mathrm{M}\right.$; Sigma-Aldrich) or with forskolin plus increasing concentrations of octreotide (range $10^{-6}-10^{-}$ ${ }^{10} \mathrm{M}$; Sandostatin, Novartis, Arnhem, the Netherlands) for 30 minutes in a $\mathrm{CO}_{2}$ incubator at $37^{\circ} \mathrm{C}$. The supernatant of the cells was collected, snap frozen on dry ice and stored at $-80^{\circ} \mathrm{C}$. cAMP levels were measured with RIA (Beckman Coulter, Woerden, the Netherlands) according to manufacturer's protocol.

\section{DNA isolation, bisulfite treatment and pyrosequencing}

DNA was isolated from untreated- and 5-aza-dC; $\left(\mathrm{BON}-1: \mathrm{EC}_{50} 100 \mathrm{nM}\right.$, QGP-1: $\left.\mathrm{EC}_{50} 50 \mathrm{nM}\right)$ treated BON-1 and QGP-1 cells, according to protocol with the Genome Wizard DNA isolation kit (Promega Corporation, Madison, USA). For bisulfite conversion $1000 \mathrm{ng}$ input DNA was used with the Zymo Research EZ DNA Zymo kit according to manufacturer's protocol (Zymo Research Corporation, Irvine, USA). Primer design was done with PyroMark Assay Design 2.0 (Qiagen N.V., Venlo, the Netherlands). Bisulfite treated DNA was aliquoted and stored at $-20^{\circ} \mathrm{C}$. PCR of bisulfite treated DNA was performed with the primers listed in Table 1 and with the following program: 5 minutes $95^{\circ} \mathrm{C}, 45$ cycles 30 seconds $95^{\circ} \mathrm{C}$ - 30 seconds $60^{\circ} \mathrm{C}-30$ seconds $72^{\circ} \mathrm{C}, 1$ cycle 10 minutes $72^{\circ} \mathrm{C}, \infty 4^{\circ} \mathrm{C}$. PCR products were analyzed on the PyroMark Q24 (Qiagen) with PyroMark Gold Q24 reagents (Qiagen) according to manufacturer's protocol

\section{Chromatin isolation}

Chromatin isolation was performed to evaluate H3K9Ac and H3K27me3 enrichment. BON-1 and QGP1 cells were plated on day 1 and grown until day 4, after which the medium was changed and 5-aza-dC (BON-1 $\mathrm{EC}_{50} 100 \mathrm{nM}$, QGP-1 EC $\left.50 \mathrm{nM}\right)$; VPA (BON-1 EC 50 $2.5 \mathrm{mM}$, QGP-1 EC $\mathrm{E}_{50} 1 \mathrm{mM}$ ); and the combination of both drugs were added, except to the control flasks. The cells were incubated for 4 days and harvested on day 8 . The cells were trypsinized and centrifuged to remove the trypsin. Cells from the same treatment condition were resuspended and pooled in $15 \mathrm{ml}$ fresh medium in a 50 $\mathrm{ml}$ tube. Formaldehyde was added to a final concentration of $1 \%$ to cross-link, and incubated rotating at room temperature for 10 minutes. Subsequently $2.5 \mathrm{M}$ glycine was added to a final concentration of $0.125 \mathrm{M}$ to quench the reaction. The fixed cells were then centrifuged at $4^{\circ} \mathrm{C}, 5$ minutes at $1500 \mathrm{rpm}$ and washed twice with icecold PBS. The cells were resuspended in $750 \mu \mathrm{PBS}$ and transferred to a $1.5 \mathrm{ml}$ tube and centrifuged at $4{ }^{\circ} \mathrm{C}$ for 5 minutes at $3000 \mathrm{rpm}$. Cells were incubated 10 minutes in $500 \mu \mathrm{l}$ nucleic lysis buffer ( $1 \%$ SDS $+50 \mathrm{mM}$ TrisHCL (pH8.1) + 10 mM EDTA (pH8.0) with PMSF on ice. Following incubation the lysates were sheared (cooled on ice), with a mean of 7 times 20 second pulses with 60 second pauses to cool. Samples were centrifuged at $4^{\circ} \mathrm{C}$ at $13,000 \mathrm{rpm}$. Shearing is performed to create chromatin fragments of 200-1000bp, which was confirmed by gel electrophoresis following DNA isolation of $50 \mu \mathrm{l}$ of the $500 \mu \mathrm{l}$ sample with 30 minutes incubation with $100 \mu \mathrm{l}$ $\mathrm{H}_{2} \mathrm{O}, 6 \mu \mathrm{l} 5 \mathrm{M} \mathrm{NaCl}$ and $2 \mu \mathrm{l}$ RNAse $\mathrm{A}(10 \mathrm{mg} / \mathrm{ml})$ at $37^{\circ} \mathrm{C}$ 
and a subsequent 2 hour incubation with adding of $2 \mu \mathrm{l}$ proteinase $\mathrm{K}(20 \mathrm{mg} / \mathrm{ml})$ at $65^{\circ} \mathrm{C}$. The DNA was purified with the Roche high pure PCR purification kit.

\section{Chromatin immunoprecipitation}

Prior to precipitation, chromatin was precleared with negative control IgG from rabbit serum for two hours, followed by incubation with protein-G magnetic beads (Invitrogen Dynal AS) for 1 hour, after which the beads were removed and discarded. A $10 \mu$ input sample was set aside and ChIP was performed overnight with $2.5 \mathrm{mg}$ H3K9Ac (ab4441, Abcam, Cambridge, UK) or H3K27me3 (ab6002, Abcam) antibodies, as well as a negative control IgG from rabbit serum, followed by 2 hours incubation with protein-G magnetic beads. Subsequently the beads are sequestered by a magnet and the supernatant removed. The beads were washed 3 times with a low salt buffer $(20 \mathrm{mM}$ Tris- $\mathrm{HCl}(\mathrm{pH} 8.0)+2 \mathrm{mM}$ EDTA $+1 \%$ Triton X-100 $+150 \mathrm{mM} \mathrm{NaCl}), 1$ time a high salt wash $(20 \mathrm{mM}$ Tris-HCl $(\mathrm{pH} 8.0)+2 \mathrm{mM}$ EDTA +1 $\%$ Triton $\mathrm{X}-100+0.1 \% \mathrm{SDS}+500 \mathrm{mM} \mathrm{NaCl})$ and 1 time a LiCl wash (10 mM Tris- $\mathrm{HCl}(\mathrm{pH} 8.0)+1$ mM EDTA $+0.25 \mathrm{M} \mathrm{LiCl}+0.5 \%$ IGEPAL $+0.5 \%$ Deoxycholate (sodium salt)) for 5 minutes at $4^{\circ} \mathrm{C}$. After a subsequent TE buffer wash, $150 \mu$ elution buffer $(25 \mathrm{mM}$ Tris- $\mathrm{HCl}$ $(\mathrm{pH} 7.5)+10 \mathrm{mM}$ EDTA $+0.5 \%$ SDS) was added to the beads as well as the input sample, the beads were incubated at $65^{\circ} \mathrm{C}$ for 30 minutes. The eluted chromatin was then transferred to clean Eppendorf tubes and together with the input samples incubated overnight with $6 \mu 15 \mathrm{M}$ $\mathrm{NaCl}$ and $2 \mu \mathrm{l}$ Proteinase $\mathrm{K}(20 \mathrm{mg} / \mathrm{ml})$. The precipitated DNA and input DNA was isolated by Roche high pure PCR purification kit and eluted in $50 \mu \mathrm{l} 2 \mathrm{O}$.

Enrichment of the $s s t_{2}$ promoter was analyzed at three positions, primer sequences are described in Table 1. Furthermore negative and positive controls were analyzed for both histone marks (data not shown). Q-PCR was performed with Roche Fast start Universal SYBR green master mix (Rox) according to protocol. The percentage recovery was calculated by $100 \% \times \mathrm{E}^{\wedge(\mathrm{CT} \text { input-adjusted - CtIP) }}$, with $\mathrm{E}$ being the efficiency coefficient of the primers. The correction factor for the adjusted CT for input DNA was calculated by $\mathrm{E}^{\wedge X}=50$, with $X$ being the correction factor. For the primer sets $-2,-1$ and tss, the efficiency factors were $1.9,2.2,1.9$, respectively.

\section{Statistics}

In order to stabilize the variance, the data was $\log$ transformed before statistical analysis. For the comparison of treatment means, the Tukey post hoc test method was applied. All data were analyzed using GraphPad (Prism 5, La Jolla, CA, USA). P values $<0.05$ were considered significant. To compare the cAMP data, we performed an F-test.

\section{ACKNOWLEDGMENTS}

This research was financially supported by Erasmus $\mathrm{MC}$ Vriendenfonds and by a donation from $\mathrm{Mr}$. and Mrs. Westra. The authors would like to thank Ing. J.H. Havermans and Dr. K. Yacqub-Usman for their advice concerning performing chromatin immunoprecipitation.

\section{CONFLICTS OF INTEREST}

LH has received investigator-initiated research grants from Ipsen and Novartis. RAF has received research grants from Novartis. WWH is in the advisory board of- and has received research support from Novartis and Ipsen.

\section{REFERENCES}

1. de Herder WW, van der Lely AJ, Lamberts SW. Somatostatin analogue treatment of neuroendocrine tumours. Postgraduate medical journal. 1996; 72:403-408.

2. Rinke A, Muller HH, Schade-Brittinger C, Klose KJ, Barth P, Wied M, Mayer C, Aminossadati B, Pape UF, Blaker M, Harder J, Arnold C, Gress T, Arnold R. Placebo-controlled, double-blind, prospective, randomized study on the effect of octreotide LAR in the control of tumor growth in patients with metastatic neuroendocrine midgut tumors: a report from the PROMID Study Group. J Clin Oncol. 2009; 27:4656-4663.

3. Caplin ME, Pavel M, Cwikla JB, Phan AT, Raderer M, Sedlackova E, Cadiot G, Wolin EM, Capdevila J, Wall L, Rindi G, Langley A, Martinez S, et al. Lanreotide in metastatic enteropancreatic neuroendocrine tumors. N Engl J Med. 2014; 371:224-233.

4. Milan SA, Yeo CJ. Neuroendocrine tumors of the pancreas. Current opinion in oncology. 2012; 24:46-55.

5. Kwekkeboom DJ, de Herder WW, van Eijck CH, Kam BL, van Essen M, Teunissen JJ, Krenning EP. Peptide receptor radionuclide therapy in patients with gastroenteropancreatic neuroendocrine tumors. Semin Nucl Med. 2010; 40:78-88.

6. van der Zwan WA, Bodei L, Mueller-Brand J, de Herder WW, Kvols LK, Kwekkeboom DJ. GEPNETs update: Radionuclide therapy in neuroendocrine tumors. Eur $\mathrm{J}$ Endocrinol. 2015; 172:R1-8.

7. Veenstra MJ, de Herder WW, Feelders RA, Hofland LJ. Targeting the somatostatin receptor in pituitary and neuroendocrine tumors. Expert Opin Ther Targets. 2013; 17:1329-1343.

8. Okuwaki K, Kida M, Mikami T, Yamauchi H, Imaizumi H, Miyazawa S, Iwai T, Takezawa M, Saegusa M, Watanabe M, Koizumi W. Clinicopathologic characteristics of pancreatic neuroendocrine tumors and relation of somatostatin receptor type $2 \mathrm{~A}$ to outcomes. Cancer. 2013; 119:4094-4102. 
9. Torrisani J, Hanoun N, Laurell H, Lopez F, Maoret JJ, Souque A, Susini C, Cordelier P, Buscail L. Identification of an upstream promoter of the human somatostatin receptor, hSSTR2, which is controlled by epigenetic modifications. Endocrinology. 2008; 149:3137-3147.

10. Petersenn S, Rasch AC, Presch S, Beil FU, Schulte HM. Genomic structure and transcriptional regulation of the human somatostatin receptor type 2. Mol Cell Endocrinol. 1999; 157:75-85.

11. Sun L, Qian Q, Sun G, Mackey LV, Fuselier JA, Coy DH, Yu CY. Valproic acid induces NET cell growth arrest and enhances tumor suppression of the receptor-targeted peptide-drug conjugate via activating somatostatin receptor type II. Journal of drug targeting. 2015:1-9.

12. Greenblatt DY, Vaccaro AM, Jaskula-Sztul R, Ning L, Haymart M, Kunnimalaiyaan M, Chen H. Valproic acid activates notch-1 signaling and regulates the neuroendocrine phenotype in carcinoid cancer cells. The oncologist. 2007; 12:942-951.

13. Evers BM, Ishizuka J, Townsend CM Jr, Thompson JC. The human carcinoid cell line, BON. A model system for the study of carcinoid tumors. Ann N Y Acad Sci. 1994; 733:393-406.

14. Kaku M, Nishiyama T, Yagawa K, Abe M. Establishment of a carcinoembryonic antigen-producing cell line from human pancreatic carcinoma. Gan. 1980; 71:596-601.

15. Vandamme T, Peeters M, Dogan F, Pauwels P, Van Assche E, Beyens M, Mortier G, Vandeweyer G, de Herder W, Van Camp G, Hofland LJ, Op de Beeck K. Whole-exome characterization of pancreatic neuroendocrine tumor cell lines BON-1 and QGP-1. J Mol Endocrinol. 2015; 54:137-147.

16. Nakayama Y, Wada R, Yajima N, Hakamada K, Yagihashi S. Profiling of somatostatin receptor subtype expression by quantitative PCR and correlation with clinicopathological features in pancreatic endocrine tumors. Pancreas. 2010; 39:1147-1154.

17. Papotti M, Bongiovanni M, Volante M, Allia E, Landolfi S, Helboe L, Schindler M, Cole SL, Bussolati G. Expression of somatostatin receptor types 1-5 in 81 cases of gastrointestinal and pancreatic endocrine tumors. A correlative immunohistochemical and reverse-transcriptase polymerase chain reaction analysis. Virchows Arch. 2002; 440:461-475.

18. O'Toole D, Saveanu A, Couvelard A, Gunz G, Enjalbert A, Jaquet P, Ruszniewski P, Barlier A. The analysis of quantitative expression of somatostatin and dopamine receptors in gastro-entero-pancreatic tumours opens new therapeutic strategies. Eur J Endocrinol. 2006; 155:849-857.

19. Mussig K, Oksuz MO, Dudziak K, Ueberberg B, Wehrmann M, Horger M, Schulz S, Haring HU, Pfannenberg C, Bares R, Gallwitz B, Petersenn S. Association of somatostatin receptor 2 immunohistochemical expression with [111In]-DTPA octreotide scintigraphy and [68Ga]-DOTATOC PET/CT in neuroendocrine tumors. Horm Metab Res. 2010; 42:599-606.
20. Portela A, Esteller M. Epigenetic modifications and human disease. Nat Biotechnol. 2010; 28:1057-1068.

21. Kulis M, Esteller M. DNA methylation and cancer. Adv Genet. 2010; 70:27-56.

22. Sawan C, Herceg Z. Histone modifications and cancer. Adv Genet. 2010; 70:57-85.

23. Karahoca M, Momparler RL. Pharmacokinetic and pharmacodynamic analysis of 5-aza-2'-deoxycytidine (decitabine) in the design of its dose-schedule for cancer therapy. Clin Epigenetics. 2013; 5:3.

24. Momparler RL. Epigenetic therapy of cancer with 5-aza2'-deoxycytidine (decitabine). Semin Oncol. 2005; 32:443-451.

25. Cincarova L, Zdrahal Z, Fajkus J. New perspectives of valproic acid in clinical practice. Expert opinion on investigational drugs. 2013; 22:1535-1547.

26. Silva MF, Aires CC, Luis PB, Ruiter JP, IJlst L, Duran M, Wanders RJ, Tavares de Almeida I. Valproic acid metabolism and its effects on mitochondrial fatty acid oxidation: a review. Journal of inherited metabolic disease. 2008; 31:205-216.

27. Gatto F, Hofland LJ. The role of somatostatin and dopamine D2 receptors in endocrine tumors. Endocr Relat Cancer. 2011; 18:R233-251.

28. Ramirez JL, Gracia-Navarro F, Garcia-Navarro S, Torronteras R, Malagon MM, Castano JP. Somatostatin stimulates GH secretion in two porcine somatotrope subpopulations through a cAMP-dependent pathway. Endocrinology. 2002; 143:889-897.

29. Nebbioso A, Carafa V, Benedetti R, Altucci L. Trials with 'epigenetic' drugs: an update. Mol Oncol. 2012; 6:657-682.

30. Nervi C, De Marinis E, Codacci-Pisanelli G. Epigenetic treatment of solid tumours: a review of clinical trials. Clin Epigenetics. 2015; 7:127.

31. Hofland LJ, van der Hoek J, van Koetsveld PM, de Herder WW, Waaijers M, Sprij-Mooij D, Bruns C, Weckbecker G, Feelders R, van der Lely AJ, Beckers A, Lamberts SW. The novel somatostatin analog SOM230 is a potent inhibitor of hormone release by growth hormone- and prolactinsecreting pituitary adenomas in vitro. J Clin Endocrinol Metab. 2004; 89:1577-1585.

32. Ferone D, van Hagen PM, van Koetsveld PM, Zuijderwijk J, Mooy DM, Lichtenauer-Kaligis EG, Colao A, Bogers AJ, Lombardi G, Lamberts SW, Hofland LJ. In vitro characterization of somatostatin receptors in the human thymus and effects of somatostatin and octreotide on cultured thymic epithelial cells. Endocrinology. 1999; 140:373-380.

33. Hofland LJ, van Koetsveld PM, Waaijers M, Zuyderwijk $\mathrm{J}$, Breeman WA, Lamberts SW. Internalization of the radioiodinated somatostatin analog [125I-Tyr3] octreotide by mouse and human pituitary tumor cells: increase by unlabeled octreotide. Endocrinology. 1995; 136:3698-3706. 